\title{
Kissing Molars İle İlişkili Dentigeröz Kist: Bir Vaka Raporu*
}

\author{
Dentigerous Cyst Related To Kissing Molars: A Case Report
}

\author{
Halim GÜLTEKİN ${ }^{1}$ (D)
}

dthalimgultekin@gmail.com

\author{
Duygu AZMAN ${ }^{2}$ (D)
}

duygudenti@hotmail.com

\author{
Melek TAȘSÖKER**2 (iD \\ dishekmelek@gmail.com
}

Alparslan ESEN ${ }^{1}$ (D)

alparslanesen@gmail.com

\section{öz}

'Kissing molars' (KM) terimi, gömülü iki mandibular molar dișin, tek bir foliküler alan içerisinde oklüzal yüzeylerinin temas halinde olduğu ve köklerinin zıt yönlere doğru baktığı nadir bir durumu tanımlamaktadır. Bu dental inklüzyon sıklıkla mandibulada tek taraflı, daha az sıklıkta bilateral, tipik olarak son iki molar dişi içermektedir. KM' nin etiyolojisi tam olarak bilinmemektedir, çenelerde hiperplastik diș folikülleri, dentigeröz kistler $(\% 33,3)$ ile ilișkili ve mukopolisakkaridoz gibi kalıtsal bir metabolik bozukluk ile iliş̧kili olabileceği düşünülmektedir. Bu vaka raporunun amacı sol posterior mandibulada KM ile birlikte görülen dentigeröz kist vakasını tanımlamak ve tedavisini sunmaktır.

Kliniğimize sol retromolar bölgesindeki ağrı şikayeti ile başvuran 25 yaşında sistemik yönden sağlıklı erkek hastanın yapılan intraoral muayenesinin ardından hastadan alınan panoramik radyografta sol mandibular 2. ve 3. molar dişlerin tek bir foliküler boşlukta oklüzal yüzeylerin birbiriyle temas halinde ve köklerinin zıt yönlere doğru bakacak şekilde gömülü pozisyonda olduğu izlendi. Gömülü sol mandibular 2. ve 3. molar dişlerin kronlarını mine-sement sınırını içine alacak șekilde saran sınırları belirgin yaklaşık $3 \times 2 \mathrm{~cm}$ boyutunda kistik lezyon tespit edildi. İncelenen lezyon dentigeröz kist ön tanısıyla ağız, diș ve çene cerrahisi anabilim dalına yönlendirildi.

KM vakaları altta yatan bir sistemik nedene veya çenelerdeki lezyonlara bağlı olarak ortaya çıkabileceğinden bu vakalarda, erken teşhis oluşabilecek komplikasyonları önlemek ve daha başarılı tedavi sağlamak için çok önemlidir.

\begin{tabular}{cccc}
\hline & Anahtar Kelimeler: Kissing molar, Dentigeröz kist, Gömülü diş & \\
\hline Geliş: 23.08.2021 & Kabul: 31.10 .2021 & Yayın: 29.12 .2021 \\
\hline
\end{tabular}

\begin{abstract}
The term "Kissing molars" (KM) describes a rare situation where the occlusal surfaces of two impacted mandibular molars are in contact within a single follicular area and their roots point in opposite directions. This dental inclusion often involves unilateral, less often bilateral, typically the last two molar teeth in the mandible.The etiology of KM is not fully known, it is thought to be associated with an inherited metabolic disorder such as hyperplastic dental follicles in the jaws, dentigerous cysts (33.3\%) and mucopolysaccharidosis. The purpose of this case report is to describe and present the treatment of a dentigerous cyst case with KM in the left posterior mandible.

Following the intraoral examination of a 25 -year-old systemically healthy male patient who presented with pain in the left retromolar region, a panoramic radiograph was taken from the patient. Panoramic radyograph showed that left mandibular 2nd and 3rd molar teeth were in a single follicular cavity in contact with the occlusal surfaces and their roots were buried in opposite directions. A cystic lesion, approximately $3 \times 2 \mathrm{~cm}$ in size, with distinct borders surrounding the crowns of impacted left mandibular 2 nd and 3rd molar teeth, including the enamel-cementum border, was detected. The examined lesion was directed to the department of oral and maxillofacial surgery with a pre-diagnosis of dentigerous cyst.
\end{abstract}

Since KM cases may arise due to an underlying systemic cause or lesions in the jaws, early diagnosis is very important in these cases to prevent possible complications and to provide more successful treatment.

Keywords: Kissing molar, Dentigerous cyst, Impacted tooth

Received: 23.08 .2021

Accepted: 31.10 .2021

Published: 29.12 .2021

Atıf / Citation: Gültekin H, Azman D, Taşsöker M, Esen A. Kissing molars ile ilişkili dentigeröz kist: Bir vaka raporu. NEU Dent J. 2021;3:143-7.

* Bu çalıșma 7-9 Mayıs 2021 tarihinde AÇBiD 14th International Online Congress'inde poster

bildiri olarak sunulmuştur.

** Sorumlu Yazar / Corresponding Author

1. Necmettin Erbakan Üniversitesi Diș Hekimliği Fakültesi Ağız, Diş ve Çene Cerrahisi AD

Konya, Türkiye

2. Necmettin Erbakan Üniversitesi Diş Hekimliği Fakültesi Ağız, Diş ve Çene Radyolojisi AD

Konya, Türkiye 


\section{GíRiş}

Erüpsiyon problemlerinden en sik etkilenen daimi dişler sırasıyla mandibular ve maksiller üçüncü molarlar, maksiller kaninler, santral kesici dişler, ikinci mandibular premolarlar ve nadiren ikinci molarlardır (tüm gömülü dişlerin $\% 0,03-0,04$ 'ü). ${ }^{1}$

'Kissing molars' (KM) terimi, gömülü iki mandibular molar dişin, tek bir foliküler alan içerisinde oklüzal yüzeylerinin temas halinde olduğu ve köklerinin zit yönlere doğru baktığı nadir bir durumu tanımlamaktadır. Bu dental patolojik durum ilk olarak 1973 yılında Van Hoof tarafından tanımlanmıș olup, Robinson ve ark. tarafindan ise 1991 yılında 'kissing molars' özel terimiyle adlandırılmıștır. ${ }^{2-4} \mathrm{Bu}$ dental inklüzyon sıklıkla mandibulada tek tarafl, daha az sıkllkta bilateral, tipik olarak son iki molar diși (ikinci ve üçüncü, nadiren üçüncü ve dördüncü süpernümerer molar) içermektedir., ${ }^{5,6} \mathrm{KM}$ vakalarının cinsiyet ayrımı bulunmamakta olup 13-50 yaş aralığında vakalar bildirilmiştir. ${ }^{6,7}$

KM'nin etiyolojisi tam olarak bilinmemekte olup çenelerde hiperplastik diş folikülleri ve dentigeröz kistler $(\% 33,3)$ ile birlikte görülebileceği bildirilmiştir. ${ }^{7-9}$ Kistik patolojinin gömülü üçüncü azı dişin mezial kökü boyunca kemikte rezorpsiyon meydana getirmesi sonucu oluşan kemik kaybının dişin devrilmesine sebep olması bu durumun nedeni olarak gösterilmektedir. ${ }^{10}$ Mukopolisakkaridoz gibi kalıtsal bir metabolik bozukluğun da KM olușumu için olası bir etiyolojik faktör olabileceği de öne sürülmüștür. Bunun nedeni mukopolisakkaridozlu hastalarda daimi dişlerin gecikmiş sürmesi olarak gösterilmiştir. ${ }^{11}$

Bu çalıșmanın amacı sol posterior mandibulada KM ile birlikte görülen dentigeröz kist vakasını tanımlamak ve tedavisini sunmaktır.

\section{OLGU SUNUMU}

Kliniğimize sol retromolar bölgesindeki ağrı şikayeti ile başvuran 25 yaşında sistemik yönden sağlıklı erkek hastanın yapılan intraoral muayenesinde mandibular sol premolar dișlerinde așırı madde kaybına sebebiyet veren derin çürükler ve mandibular sol molar dişlerinin ağızda yer almadığı tespit edildi. Hastadan alınan panoramik radyografta mandibular sol 2 . ve 3. molar dişlerin tek bir foliküler boşlukta oklüzal yüzeylerin birbiriyle temas halinde ve köklerinin zit yönlere doğru bakacak şekilde gömülü pozisyonda olduğu izlendi. Gömülü sol mandibular 2. molar ve 3. molar dişlerin kronlarını mine-sement sınırını içine alacak şekilde saran sınırları belirgin yaklaşık $3 \times 2$ $\mathrm{cm}$ boyutunda kistik lezyon tespit edildi. Kistik lezyonun inferior sınırının mandibular kanalın superior duvarıyla ilişkili olduğu izlendi. Hastada parestezi bulgusuna rastlanılmadı (Resim 1). İncelenen lezyon dentigeröz kist ön tanısıyla ağız, diș ve çene cerrahisi anabilim dalına yönlendirildi.

Resim 1: Hastadan alınan panaromik radyograf

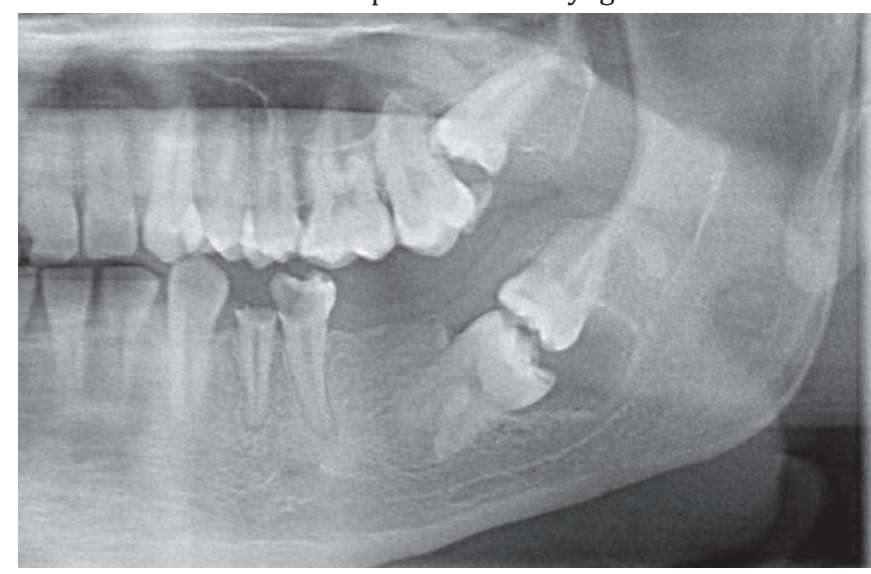

Ağız, diș ve çene cerrahisi kliniğinde hastadan bilgilendirilmiş onam alınarak lokal anestezi altında diş çekimini içeren bir tedavi planı oluşturuldu. Cerrahi operasyon rejyonel ve infiltrasyon anestezisi altında inferior alveolar, bukkal ve lingual sinirleri bloke ederek gerçekleştirildi. Mandibula posterior bölgede sol mandibular 2. premolar dişin distalinden retromolar bölgeye uzanan kret tepesinden düz bir insizyon yapıldı. Daha sonra mukoperiosteal flap kaldırılarak açığa çıkarılan korteks, frezler yardımı ile uzaklaştırılıp mandibular sol 2. ve 3. molar dişlerin kronlarını açığa çıkaran osteotomi gerçekleştirildi (Resim 2).

Resim 2: Operasyon bölgesine atılan insizyon ve dişlerin kronlarının frezler yardımı ile açığa çıkarılması.

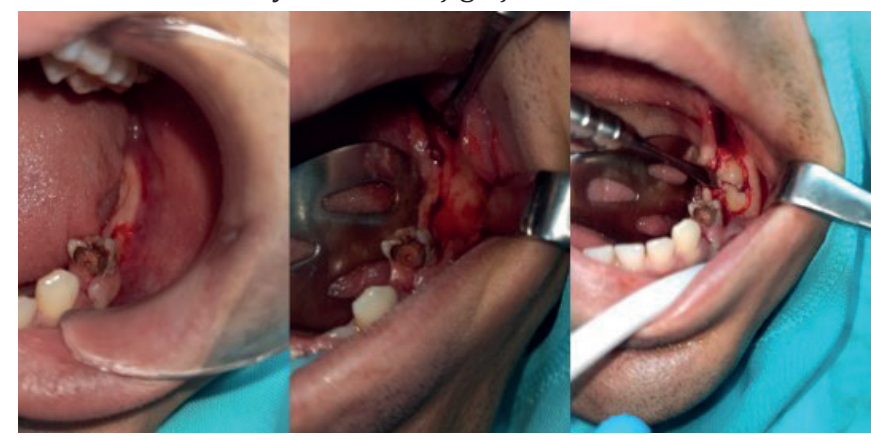

Osteotomi sonrası kemik kaybını en aza indirmek ve ekstraksiyonu kolaylaştırmak amaciyla mandibular sol 2. ve 3. molar dişler frezler yardımıyla parçalara ayrılarak tamamen çıkarıldı (Resim 3).

Resim 3: Çıkarılan 37 ve 38 numaralı dișler

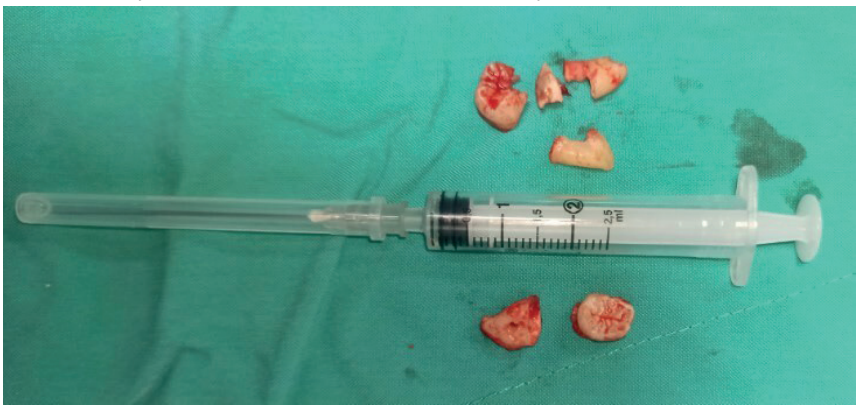


İnferior alveolar sinirin (IAN) yakınlığı nedeniyle nöral hasar vermekten kaçınmak için intraoperatif olarak azami özen gösterildi. İlgili dişlerin etrafını saran kistik lezyon tamamen enükle edilerek soket salin solüsyonuyla iyi bir șekilde temizlendi. Hemostaz sağlanıp, yara bölgesi primer kapatılarak hastaya antibiyotik, analjezik ve antiseptik gargara reçete edildi (Resim 4).

Çıarılan kitle \%10'luk formalin ile fikse edilerek histopatolojik incelemeye gönderildi. (Resim 5).

Resim 4: Operasyon sonrası kavite ve yaranın primer kapatılması

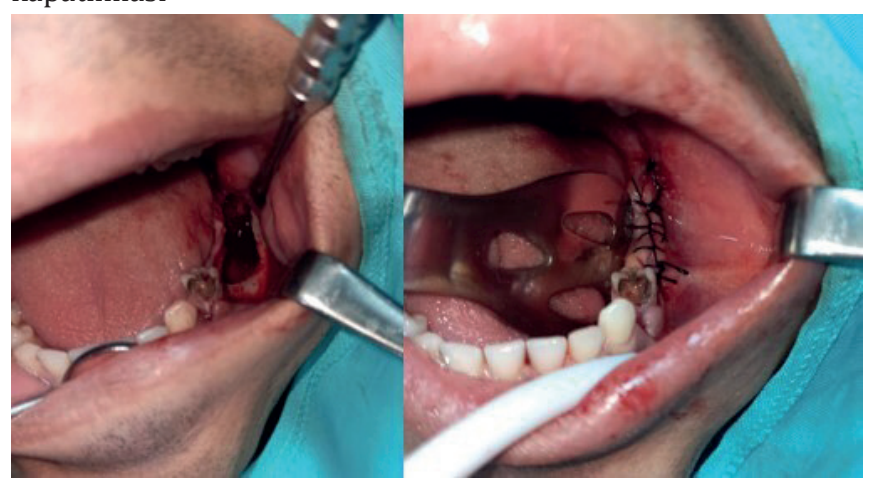

Resim 5: \%10’luk formalin solüsyonu içerisindeki kitle

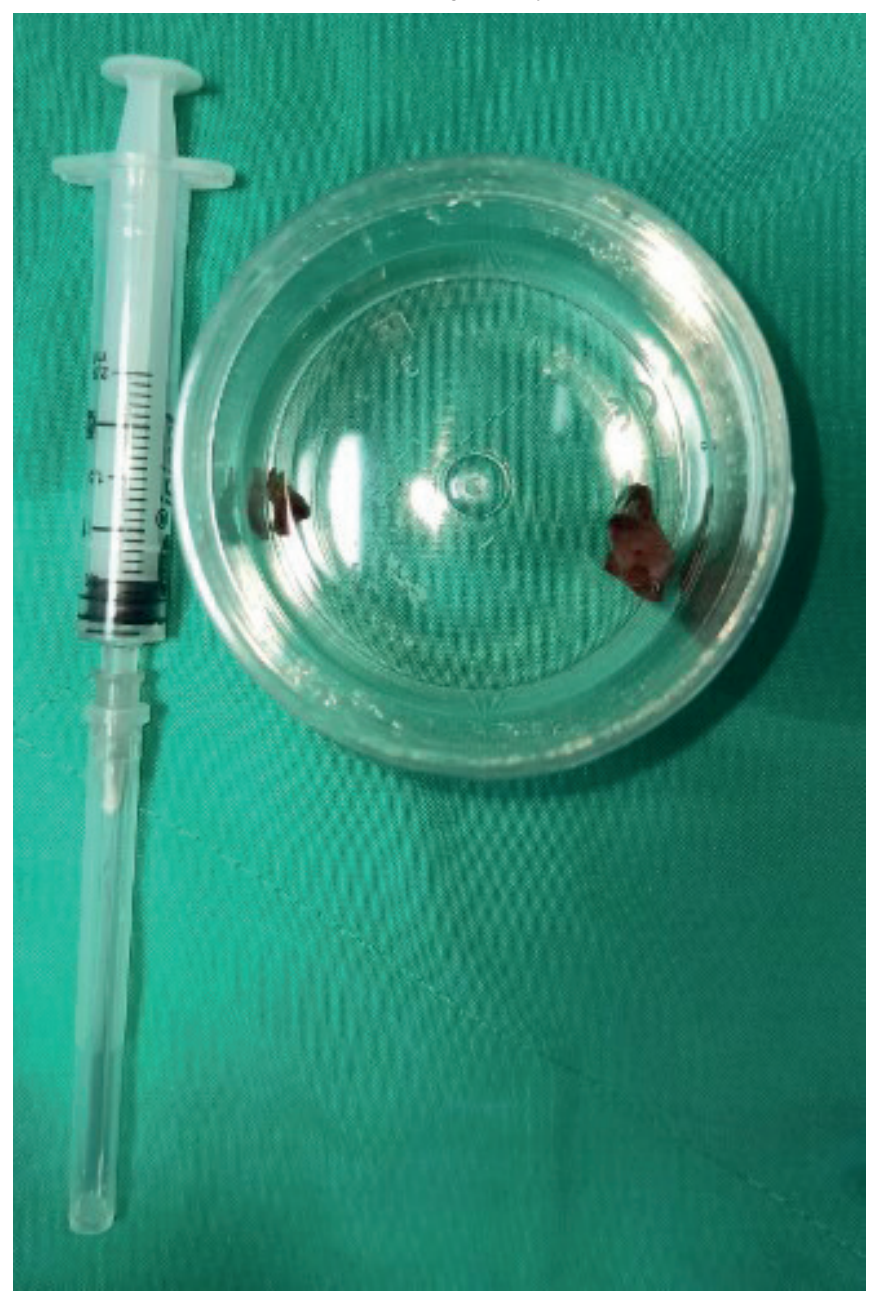

Histopatalojik inceleme kistik lezyonun dentigeröz kist olduğunu ortaya koydu. Ameliyatı takiben 10. gün hastadan suturlar alındı. Ameliyat sonrası operasyon bölgesinde ağrı, parestezi/anestezi veya enfeksiyon gibi herhangi bir komplikasyon görülmemiştir.

\section{TARTISSMA}

İlk olarak 1973'te tanımlanan KM terimi, gömülü mandibular ikinci ve üçüncü molar dişlerin oklüzal yüzeylerinin birbirine temas etmesi anlamında kullanılmıș olup 2005 yılında Bakaeen ve Baqain tarafından mandibular üçüncü molar ve dördüncü süpernümerer dişleri arasında bilateral KM vakası yayınlanmıștır. ${ }^{12}$ Olgumuzda gömülü ikinci ve üçüncü mandibular molar dişler arasında KM inklüzyonu görülmektedir.

Gömülü dişlerin tanısı klinik olarak arkta diş eksikliği veya etkilenen tarafta șișlik meydana gelmesi ile konulabilmektedir. Gömülü üçüncü molarların incelemesinde, panaromik radyograf en kullanışlı ve güvenilir radyograf olup çoğu durumda altın standart olarak kabul edilmektedir. Anatomik yapılar ile gömülü diş kökleri veya patolojik lezyonlar arasındaki üç boyutlu ilişkiyi göstermek için daha ileri araștırmalar için konik ıșınlı bilgisayarlı tomografi (KIBT) önerilmektedir. ${ }^{13}$ Hastanın başvurduğu dönemde radyoloji birimindeki teknik aksaklıklar nedeniyle KIBT incelemesi yapılamadı ve KM tanısı panoramik radyograf aracılığıyla konuldu.

Literatürde bilinen çok sayıda KM vakası bulunmakta olup sıklıkla mandibulada tek taraflı, daha az sıklıkta bilateral, tipik olarak son iki molar diși içermektedir. ${ }^{5,6} \mathrm{KM}$ vakalarının cinsiyet ayrımı bulunmamakta olup 13-50 yaș aralığında vakalar bildirilmiştir. ${ }^{6,7}$ Hastamız 25 yașında erkek olup mandibulada tek taraflı ikinci ve üçüncü molar dişlerini içeren KM patolojisine sahiptir.

KM'ler 3 tipte sınıflandırılabilirler. Bu sınıflandırmaya göre; Sınıf I etkilenmiș birinci ve ikinci molar dișlerini, Sınıf II ikinci ve üçüncü molar dişlerini ve Sınıf III üçüncü ve dördüncü molar dişlerini etkilenmiştir. Bu sinıflamaya ek olarak True-KM ve Pseudo-KM sınıflaması eklenmiş olup Pseudo-KM sınıflamasında dişlerin oklüzal yüzeyleriyle yakın teması yoktur. Bu sınıflandırmanın gömülü dişlerin maksilla veya mandibuladaki önemli anatomik yapılarla ilișkisi (maksiller sinüs, mandibular kanal), kemikteki derinliği, karșısındaki dișe göre angulasyonu, mandibulanın alt sınırı veya bukkal veya lingual kısımdaki lokalizasyonu ile ilgili ayrıntıları bize vermeme gibi limitasyonları mevcuttur. Dolayısıyla, KM'nin sınıflandırılması için, yukarıdaki sınırlamaları ele alan, teșhis sürecini ve tedavi planını değiștirebilecek olası altta yatan sistemik hastalıkları göz önünde 
bulunduran sistematik bir sinıflandırma sistemine ihtiyaç vardır. ${ }^{5,9,10} \mathrm{Bu}$ sınıflandırmaya göre olgumuz True-KM Sinıf II olarak değerlendirilebilir.

KM'nin etiyolojisi, bazı teoriler öne sürülmesine rağmen belirsizliğini korumaktadır. KM vakalarının mukopolisakkaridoz teşhisi konulan birden fazla hastada görülmesi bu patolojinin mukopolisakkaridoz ile ilișkilendirilmesine neden olmuştur. ${ }^{14}$ Bunun nedeni mukopolisakkaridozlu hastalarda daimi dişlerin gecikmiş sürmesine bağlanmıştır. ${ }^{15}$ Mukopolisakkaridoz, lizozomal enzim bozukluğuna neden olan ve kornea, kalp, karaciğer, merkezi sinir sistemi, kemik ve diğer bölgelerde glikozaminoglikan birikimine yol açan genetik bir hastalıktır. ${ }^{16}$ Olgumuzda klinik ve radyolojik olarak mukopolisakkaridoz dahil olmak üzere herhangi bir sistemik hastalık bulgusuna rastlanılmamıştır.

Bazı araştırmacılar KM'leri izole olaylar olarak kabul etmektedir. Bu durumun diș tomurcuğu veya diş folikülünün gelişim yönünün anormal pozisyonundan ve diş folikülü enzimlerinin (matriks metalloproteinaz) üstteki alveolar kemiğin rezorpsiyonunu uygun şekilde başlatma veya devam ettirme yeteneğindeki başarısızlıktan kaynaklandığını ileri sürmektedirler. ${ }^{5}$

Gömülü dișler etrafındaki normal perikoronal radyolusensinin 2-3 mm aralığında olduğu kabul edilmektedir, bu boyutta artıș meydana gelmesi hiperplastik folikül (yaklaşık 3-5 mm) ve gelişimsel odontojenik kistleri ayırıcı tanıda düşündürmelidir. ${ }^{17} \mathrm{KM}^{\prime}$ lerin dentigeröz kist $(\% 33,3)$ ile ilişki olduğu ve dentigeröz kistin birinci ve ikinci molar dișlerin sürmesine engel olabileceği görülmüștür. ${ }^{9}$ Kistik patolojinin gömülü üçüncü azı dişin mezial kökü boyunca kemikte rezorpsiyon meydana getirmesi sonucu oluşan kemik kaybının dişin devrilmesine sebep olması bu durumun nedeni olarak gösterilmektedir. ${ }^{10}$ Dentigeröz kistler, ameloblastomlar, skuamöz hücreli karsinomlar ve epidermoid karsinomlar gibi çeşitli patolojilere dönüşebileceğinden KM'ler çevresindeki yumuşak dokudaki değișiklikleri dikkatlice incelemek önemlidir. ${ }^{13}$ Bizim hastamızda KM ile ilişkili patolojik lezyonun histopatolojik incelenmesi dentigeröz kist olarak sonuçlanmıştır.

Gömülü dişler tümörlere, kist oluşumuna, tekrarlayan perikoronite veya internal ve eksternal kök rezorpsiyonuna neden olabilmektedir. Gömülü dişlerin derinliği, komşu dişlerin kök rezorpsiyonu, dişin vertikal ramus ile ilişkisi, kistik lezyonlar, köklerin şekli ve açılanmalar dikkatle değerlendirilmesi gereken diğer faktörlerdir. ${ }^{18}$

KM için literatürde az sayıda tedavi seçeneği tanımlanmış olup tercih edilen tedavi genellikle dişlerin cerrahi olarak çıkarılmasıdır. Diğer tedaviler, gömülü dişlerin ortodontik tedavisi ve radyolojik ta- kiptir. Bununla birlikte cerrahi müdahaleden sonra ameliyat sırasında veya postoperatif olarak görülebilecek komplikasyonlar olarak mandibula kırıkları, dry soket, inferior alveolar $(\% 0,5$ ile 5$)$ ve lingual sinirde hasar $(\% 0,2$ ile 2$)$, osteomiyelit ve temporomandibular eklem bozuklukları görülebilmektedir. $^{19,20}$

Hastamızın ikinci ve üçüncü molar dişlerinin çekimi yapıldı ve hastaya yaklaşık iki ay yumuşak diyet uygulandı. Cerrahi sonrası herhangi bir komplikasyon ile karşılașılmadı.

\section{SONUC}

KM vakaları altta yatan bir sistemik nedene veya çenelerdeki lezyonlara bağlı olarak ortaya çıkabileceğinden bu vakalara, KM'ye neden olabilecek lokal veya sistemik faktörler düșünülerek yaklaşılmalıdır. Erken teşhis oluşabilecek komplikasyonları önlemek ve daha başarılı tedavi sağlamak için çok önemlidir. KM'lerin çıkarılması için ilgili bölgenin anatomisinin çene fraktürü ve sinir hasarına neden olmamak için kapsamlı bir şekilde ele alınması gerektiği unutulmamalıdır.

\section{KAYNAKLAR}

1. Bourzgui F. Orthodontics: Basic Aspects and Clinical Considerations. 2021. p.247-50.

2. Nedjat-Shokouhi B, Webb RM. Bilateral kissing molars involving a dentigerous cyst: report of a case and discussion of terminology. Oral Surg. 2014;7:107-10.

3. Juneja M. Not kissing. Br Dent J. 2008;204:597.

4. Robinson, JA, Gaffney W, Soni NN. Bilateral 'kissing'molars. Oral Surg Oral Med Oral Pathol. 1991;72:760.

5. Menditti D, Laino L, Cicciù M, Mezzogiorno A, Perillo L, Menditti M, et al. Kissing molars: report of three cases and new prospective on aetiopathogenetic theories. Int J Clin Exp Pathol. 2015;8:15708-18.

6. Kiran HY, Bharani KSNS, Kamath RA, Manimangalath G, Madhushankar GS. Kissing molars and hyperplastic dental follicles: report of a case and literature review. Chin J Dent Res. 2014;17:57-63.

7. Akbulut N, Tatidze M, Kolsuz ME, Sindel A, Colok G. Kissing molars: a rare condition of two case. AU Dis Hek Fak Derg. 2009;36:169-72.

8. Yaman D, Akay G, Güngör K. Multiple dentigerous cysts with radiological findings in a non-syndromic patient. Atatürk Üniv Diş Hek Fak Derg. 2020;30:1225.

9. Mascarenhas R, Shetty S, Husain A, Shahista P. Kissing molars: An unusual unexpected impaction. Arch Med Health Sci. 2013;1:52-3.

10. Gulses A, Varol A, Sencimen M, Dumlu A, A study of impacted love: kissing molars. Oral Health Dental Manag. 2012;11:185-88. 
11. McIntyre G. Kissing molars: an unexpected finding. Dent Update.1997;24:373-4.

12. Bakaeen G, Baqain ZH. Interesting case: kissing molars. Br J Oral Maxillofac Surg. 2005;43:534.

13. Yanik S, Ayranci F, İșman Ö, Büyükçikrikci Ş, Aras MH. Study of kissing molars in Turkish population sample. Niger J Clin Pract. 2017;20:659-64.

14. Nakamura T, Miwa K, Kanda S, Nonaka K, Anan H, Higash S, et al. Rosette formation of impacted molar teeth in mucopolysaccharidoses and related disorders. Dentomaxillofac Radiol. 1992;21:45-9.

15. Smith KS, Hallett KB, Hall RK, Wardrop RW, Firth N. Mucopolysaccharidosis: MPS VI and associated delayed tooth eruption. Int J Oral Maxillofac Surg. 1995;24:176-80.
16. Graupman P, Pan D, Konair B, Hartung S, McIvor S, Whitley C, et al. Craniofacial abnormalities in a murine knock-out model of mucopolysaccharidosis I H: A computed tomography and anatomic study. J Craniofac Surg. 2004;15:392-8.

17. Agarwal A, Mittal G, Uppada U.K. Cuddling teeth: A new terminology. Ann Maxillofac Surg. 2019;9:53.

18. Krishnan B. Kissing molars. Br Dent J. 2008;204:2812 .

19. McCoy JM. Complications of retention: pathology associated with retained third molars. Atlas Oral Maxillofacial Surg Clin North Am. 2012;20:177-95.

20. Giraldi Neto FO, Rocha Júnior HV, Martinez Júnior W, Duarte BG, Salgueiro DG, Sant'ana E. Interesting cases of kissing molars. Report of two cases. Rev Odontol Unesp. 2012;41:292-5. 